\title{
SMALL FOOTPRINT CONTINUOUS FLOW PCR DEVICES FOR A 96-WELL CFPCR MULTI-REACTOR PLATFORM
}

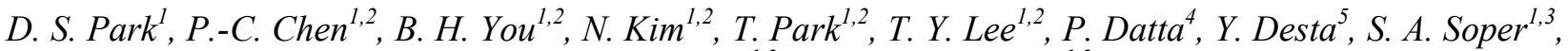 \\ D. E. Nikitopoulos ${ }^{1,2}$, and M. C. Murphy ${ }^{l, 2}$ \\ ${ }^{1}$ Center for Bio-Modular Multi-Scale Systems, ${ }^{2}$ Department of Mechanical Engineering \\ ${ }^{3}$ Department of Chemistry, ${ }^{4}$ Center for Advanced Microstructures and Devices \\ Louisiana State University, Baton Rouge, LA, USA \\ ${ }^{5}$ BioFluidica Microtechnologies, Baton Rouge, LA, USA
}

\begin{abstract}
Incorporation of spiral continuous flow $(\mathrm{CF})$ polymerase chain reaction (PCR) devices into a 96-well titer plate format will enable highly parallel analyses of many nucleic acids under steady-state temperature control for the realization of a high throughput CFPCR multi-reactor platform. Prior to realization of the full platform, verifying the feasibility of small footprint CFPCR devices, each device confined to a footprint of $8 \times 8 \mathrm{~mm}^{2}$, throughout the manufacturing and amplification processes was essential. Small footprint, CFPCR devices in a CFPCR multi-reactor module were designed and double-side hot embossed on one side of a substrate and structures for thermal isolation on the other to improve thermal management. Successful amplification of 99 bp target DNA fragments from $\lambda$-DNA template was demonstrated in the small footprint, 20- and 25-turn CFPCR devices.
\end{abstract}

\section{INTRODUCTION}

The polymerase chain reaction (PCR) is a powerful technique for DNA amplification. It has been widely used in nucleic acid analysis for diverse fields such as molecular diagnosis, treatment monitoring, food technology, forensics, agriculture, and environmental sciences $[1,2]$. Target DNA can be exponentially amplified through multiple, multi-step temperature cycles: $90-95^{\circ} \mathrm{C}$ for denaturation of double-stranded target DNA molecules, $50-70^{\circ} \mathrm{C}$ for annealing of primers to single-stranded DNA target sites, and $70-77^{\circ} \mathrm{C}$ for primer extension with a thermostable DNA polymerase. Most commercial PCR instruments are bulky and have high thermal capacitance and slow heat transfer. These lead to high power requirements and limited reaction speeds due to the constrained heating and cooling rates.

Many efforts have been made to miniaturize PCR in Si, glass, and polymers using microelectromechanical systems (MEMS) technologies for the faster reaction speeds and reduced reagent consumption over commercial PCR instruments [3]. Micro chamber-type stationary PCR devices demonstrated faster amplification due to lower thermal capacitance and faster heat transfer [4-5]. In contrast, microfabricated continuous flow PCR (CFPCR) devices can provide the advantages of steady-state temperature control and much shorter times required to heat and cool only the fluidic PCR mixtures in microchannels compared to micro chamber-type PCRs [2, 6-7].

For parallel analysis of many nucleic acids in high throughput applications such as exploitation of the accumulated genetic information from the Human Genome Project, several micro chamber-type PCR multi-reactors have been reported. Liu et al. developed an integrated PCR-CE array, glass-PDMS microdevice with resistance temperature detectors and heaters for genetic analysis [8]. A miniaturized PCR multi-chamber array for high throughput PCR was fabricated using several Si micro chambers with microfabricated heaters and sensors, and integrated onto a printed circuit board substrate using flip-chip bonding [9].

In order to overcome the slow, transient temperature control in the micro chamber-type PCR multi-reactors, microfabricated CFPCR devices can be incorporated into a polymer 96-well titer plate format [10] for the realization of a high throughput CFPCR multi-reactor platform at significantly lower cost. Figure 1 shows a schematic representation of a CFPCR multi-reactor platform, consisting of three key modules including a fluidic control module, a CFPCR multi-reactor module, and a heater module. PCR samples are introduced into common inlet ports and distributed to the inlet vias in the fluidic control network, amplified in the CFPCR multi-reactor platform, and collected from individual outlet ports using standard multi-pipettes and/or robotic equipment for PCR analysis. A heater array with precise temperature controllers can be realized using metal blocks for uniform temperature distribution with commercial strip heaters and thermocouples.

Prior to realization of the full platform, verifying the feasibility of small footprint CFPCR devices, with each device confined to a footprint of $8 \times 8 \mathrm{~mm}^{2}$, in a $1^{\text {st }}$ generation CFPCR multi-reactor module was essential throughout the manufacturing and amplification processes. Small footprint, double-sided CFPCR devices were designed, double-side hot embossed, and used to amplify DNA fragments as part of a 96-well CFPCR multi-reactor platform.

\section{DESIGN OF A CFPCR MULTI-REACTOR MODULE}

A single, spiral-type CFPCR device in a hot embossed polycarbonate (PC) chip was demonstrated to investigate its performance as a function of reaction speed and identify the

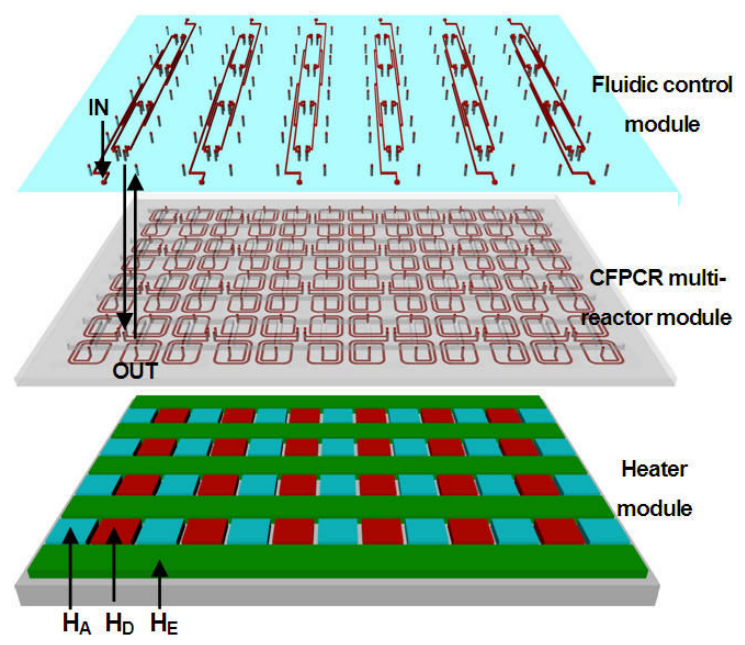

Figure 1: Schematic representation of a CFPCR multi-reactor platform with three key modules: a fluidic control module, a CFPCR multi-reactor module, and a heater module. $H_{D}$ denotes for denaturation heaters $\left(90-95^{\circ} \mathrm{C}\right), H_{A}$ for annealing heaters $\left(50-70^{\circ} \mathrm{C}\right)$, and $\mathrm{H}_{E}$ for extension heaters $\left(70-77^{\circ} \mathrm{C}\right)$. 
residence time limits for DNA amplification [7]. The spiral-type CFPCR device concept was implemented in the design of a single-sided $1^{\text {st }}$ generation CFPCR multi-reactor module and manufacturing of a single-sided 96-well CFPCR module was successfully demonstrated [11]. In order to utilize double-sided hot embossing of a 96-well CFPCR multi-reactor chip, two 6-inch large area mold inserts were designed: a nickel mold insert with the microfluidic channels for the CFPCR devices on one side, and a brass mold insert for the grooves and fins for thermal isolation on the other side with alignment marks (Fig. 2).

For the design of a nickel mold insert, each CFPCR device was confined in the effective area of $8 \times 8 \mathrm{~mm}^{2}$ because of the standardized format of the 96-well titer plate used [10]. A set of twelve CFPCR devices (channel widths: 10 40 $\mu \mathrm{m}$, depth: $40 \mu \mathrm{m}$, channel wall width: 10-55 $\mu \mathrm{m}$ ) with 20- and 25-turns was designed and extended to a 96-well format (Fig. 2(a)). The channel widths and lengths in the extension zone of each device were doubled compared to those in the denaturation and extension zones for keeping the residence time ratio of $1: 1: 4$ (denaturation : annealing : extension) [7]. Sharing of temperature zones for four adjacent PCR devices was used for efficient thermal control and use of fewer heaters and thermocouples (Fig. 3) and extended to all 96 CFPCR devices.

Grooves (width: $1 \mathrm{~mm}$, depth: $1.2 \mathrm{~mm}$ ) were used between different temperature zones in the design of a brass mold insert for thermal isolation to improve thermal management [12]. Additional fins (width: $0.4 \mathrm{~mm}$, height: $1.2 \mathrm{~mm}$ ) were used inside the grooves for the transition from the denaturation to the annealing zones (Figs. 4(a) and (b)). The temperature distribution of four adjacent CFPCR devices on one side with grooves and fins on the other side were estimated via finite element simulations with ANSYS (v11.0,

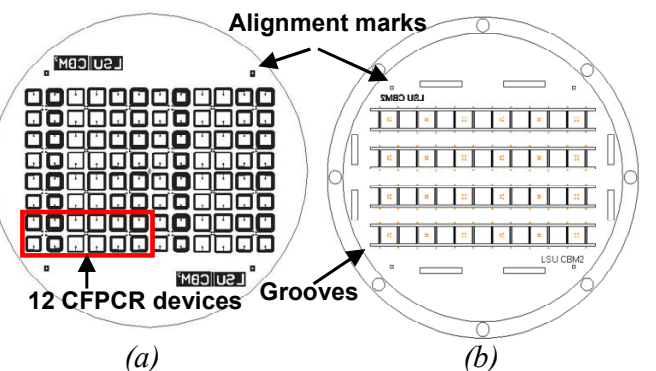

Figure 2: Layouts of (a) a nickel mold insert with a set of twelve CFPCR devices and (b) a corresponding brass mold insert with grooves and alignment marks.

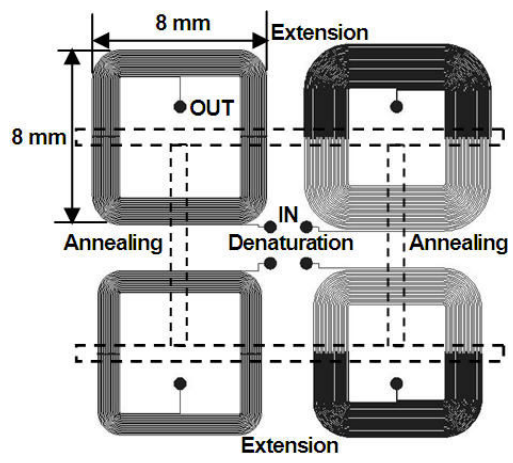

Figure 3: A layout of four CFPCR devices (each device in $8 \times 8$ $\mathrm{mm}^{2}$ ) sharing temperature zones for more efficient thermal control (dotted lines show grooves on the backside).

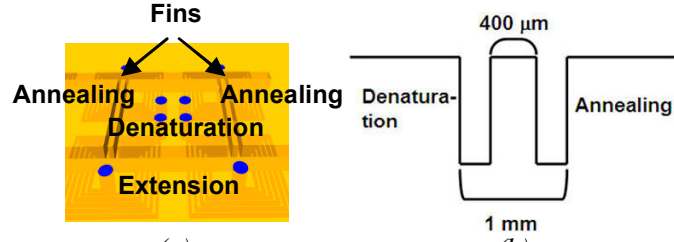

(a)

(b)

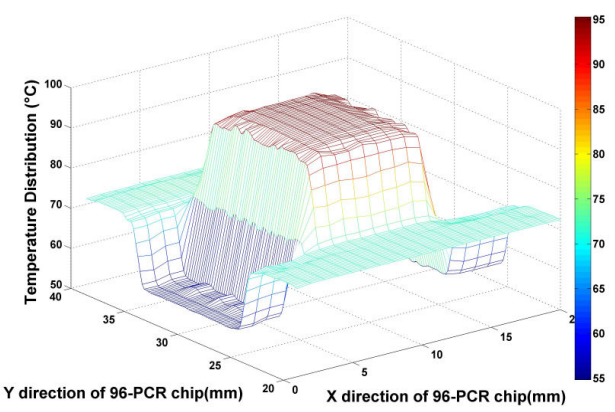

(c)

Figure 4: (a) 3-D view of CFPCR devices with grooves and fins, (b) a cross-section view of grooves and fins, and (c) temperature distribution of four adjacent CFPCR devices obtained via FE simulations with ANSYS (v11.0, Canonsburg, PA).

Canonsburg, PA) and the desired distinct temperature transitions between the different temperature zones were observed (Fig. 4(c)).

\section{FABRICATION OF A CFPCR MULTI-REACTOR MODULE}

A CFPCR multi-reactor module with small footprint CFPCR devices was fabricated and manufacturing feasibility was carefully investigated throughout the fabrication of two nickel and brass mold inserts, double-sided micro molding, sealing by thermal fusion bonding, and leakage testing.

Fabrication of a nickel mold insert was reported elsewhere [11, 13]. In brief, electroplating templates were prepared by SU-8 based optical lithography on $\mathrm{Si}$ substrates with an electron beam evaporated seed layer of $\mathrm{Cr} / \mathrm{Au}(20 \mathrm{~nm} / 50 \mathrm{~nm})$. Nickel overplating was carried out to fabricate metallic mold inserts in a custom-designed electroplating setup using a nickel sulfamate solution. Post-plating processes were carried out to produce a nickel mold insert mounted in a stainless steel (SS) hot embossing fixture, including: planarization of the overplated nickel mold insert surface, water jet cutting to a circular shape, removal of the $\mathrm{Si}$ substrate and SU-8, and mounting of the planarized nickel mold insert onto the SS fixture using laser-welding. A brass mold insert was precisely machined using a micro-milling machine (KERN MMP2522, KERN Micro- und Feinwerktechnik GmbH \& Co. KG, Germany). Fig. 5(a) shows an image of the high precision and high quality nickel and brass mold inserts.

Double-sided micro molding was done in polycarbonate (PC, $2.3 \mathrm{~mm}$ thick, Lexan 9034 sheet, GE Structured Products, Pittsfield, MA) using hot embossing with two metallic mold inserts. A molding pressure of about $160 \mathrm{psi}$ was used for one minute at a mold temperature of $187^{\circ} \mathrm{C}$ and the demolding temperature was $140^{\circ} \mathrm{C}$. Acceptable replication fidelity over the entire surface area was obtained, but some CFPCR devices with $10 \mu \mathrm{m}$ wide microchannel walls (height: $40 \mu \mathrm{m}$ ) showed incomplete filling and deformation. Alignment accuracy between the top and bottom reservoirs was within $100 \mu \mathrm{m}$ (Fig. 5(b)), which can be improved by further alignment process optimization. Figure 5(c) shows fluidic paths 
between the top and bottom reservoirs machined into the hot embossed CFPCR multi-reactor PC chips using laser ablation (Resonetics Rapid $\mathrm{X}^{\circledR} 1000$ Series laser system, Nashua, NH).

Sealing of the molded PC chips with PC covers $(250 \mu \mathrm{m}$ thick) was done in a custom-designed thermal bonding apparatus (Fig. 5(d)). The apparatus was composed of two stainless steel plates with 35 evenly spaced spring plungers [11]. Wing-nuts were used to compress the spring plungers, applying evenly distributed, multiple point loads on the glass plates, resulting in a more uniform load applied to the polymer chips. The gap between the two steel plates was used to determine the total load applied based on a calibration curve for compressed displacement of the spring plunger tips as a function of the applied load from a load cell. The bonding temperature and bonding pressure were varied parametrically for a fixed bonding time to determine the best conditions for acceptable sealing over the large surface area. A typical sealed PC chip, thermally bonded at a bonding temperature of $154^{\circ} \mathrm{C}$ and bonding pressure of $110 \mathrm{lb}$-force for a fixed bonding time of 2 hours, can be seen in Figure 5(e). A close-up of the sealed microchannels confirmed good sealing without deformation, even in the areas where grooves and fins were present underneath (Fig. 5(f)).

The sealed PC chips were cut into 10-well or 12-well sets for easier leakage and amplification testing (Fig. 6(a)). Two poly ether ether ketone (PEEK) capillaries (1543, Upchurch, Oak Harbor, WA) were inserted into inlet and outlet of CFPCR devices and fixed by epoxy. Flow of a fluorescent dye through the system confirmed

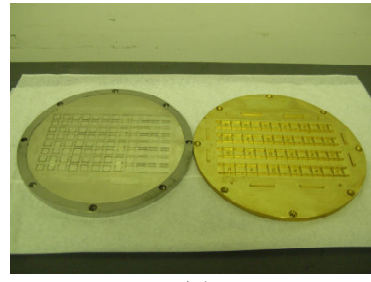

(a)

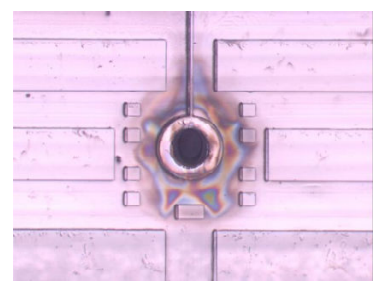

(c)

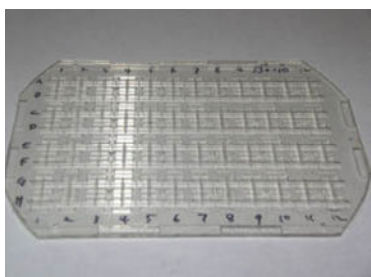

(e)

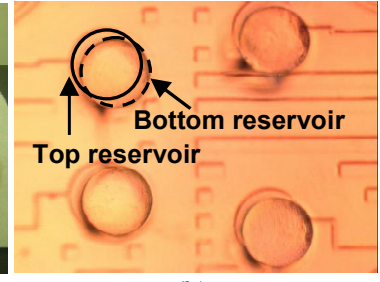

(b)

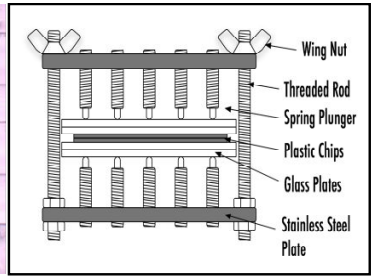

(d)

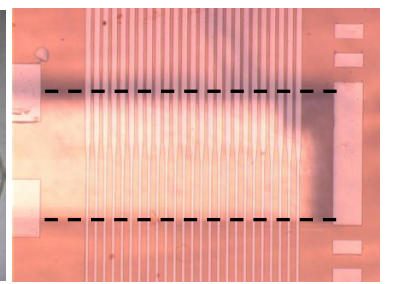

(f)
Figure 5: Images of (a) a nickel (left) and a brass (right) mold inserts, (b) four pairs of top and bottom reservoirs in a double-side molded chip, (c) a fluidic path between top and bottom reservoirs made by laser ablation, (d) a schematic view of the custom-designed thermal bonding apparatus, (e) a sealed, $1^{\text {st }}$ generation 96-well CFPCR multi-reactor module in PC, and (f) a close-up view of sealed microchannels (dotted lines show grooves on the backside).

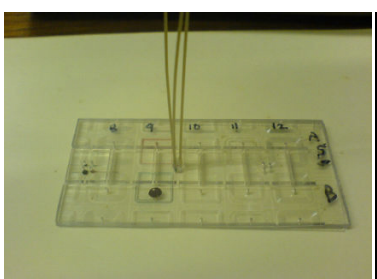

(a)

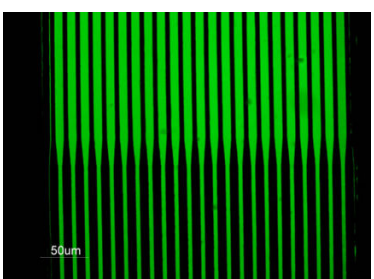

(b)
Figure 6: Images of (a) leakage testing setup using fluorescent dye with a sealed chip, cut into a 10-well (or 12-well) format; and (b) $40 \mu \mathrm{m}$ wide microchannels in the extension zone and 20 $\mu m$ wide microchannels in the denaturation (or annealing) zone filled with fluorescent dye showing no leakage between microchannels.

no leakage between the microchannels (Fig. 6(b)) and showed smooth flow of the dye for CFPCR devices with microchannel widths of $20 \mu \mathrm{m}$ or larger.

\section{DNA AMPLIFICATION}

Small footprint, 20- and 25-turn CFPCR devices with microchannel widths of $20 \mu \mathrm{m}$ or larger were used for verifying the DNA amplification capability. The overall dimensions and volumes of the devices were: the width of the microchannels in the extension zone was $40 \mu \mathrm{m}$ (channel wall width: $20 \mu \mathrm{m}$ ); the widths of the microchannels in the denaturation and annealing zones was $20 \mu \mathrm{m}$ (channel wall width: $40 \mu \mathrm{m}$ ); the depth of the microchannels for all temperature zones was $40 \mu \mathrm{m}$; and the enclosed volumes were $739 \mathrm{~nL}$ for a 20-turn CFPCR device and $990 \mathrm{~nL}$ for a 25-turn CFPCR device, respectively. The DNA template was a $48 \mathrm{kbp}$ $\lambda$-DNA c1857Sam7. Primers were designed to generate $99 \mathrm{bp}$ DNA amplicons. The forward primer was $25 \mathrm{bp}$ and its sequence was 5'-GATGAGTTCGTGTCCGTACAACTGG-3'. The reverse primer was $24 \mathrm{bp}$ and its sequence was 5'-GACGGGCAATCA GTTCATCTTTCG-3'. The PCR cocktail contained $10 \mathrm{mM}$ Tris- $\mathrm{HCl}\left(\mathrm{PH} 8.3\right.$ ), $1.5 \mathrm{mM} \mathrm{MgCl}_{2}$, and $50 \mathrm{mM} \mathrm{KCl}$. The concentrations of the nucleotides were $200 \mu \mathrm{M}$, the template was 5 $\mathrm{ng} / \mu \mathrm{l}$, each forward and reverse primer was $0.2 \mu \mathrm{M}$, bovine serum albumin (BSA) was $0.5 \mu \mathrm{g} / \mu \mathrm{l}$, and the Taq DNA polymerase was 0.1 units $/ \mu 1$. This DNA cocktail was amplified in a bench-top thermal cycler to validate the composition and as a reference to the CFPCR results. The cycling conditions were $2 \mathrm{~min}$ at $94^{\circ} \mathrm{C}$ for preheating, $7 \mathrm{~min}$ at $72^{\circ} \mathrm{C}$ for a final extension, and 20 cycles consisting of denaturation for 1 minute at $94^{\circ} \mathrm{C}$, annealing for 1 minute at $63^{\circ} \mathrm{C}$, and extension for 1 minute at $72^{\circ} \mathrm{C}$.

The single CFPCR device was placed on three separate copper plates [12] to maintain the three distinct temperature zones of $94^{\circ} \mathrm{C}$ (denaturation), $63^{\circ} \mathrm{C}$ (annealing), and $72^{\circ} \mathrm{C}$ (extension). Thermal double-sided tape was used to assure the good contact between the copper plates and the device. The DNA cocktail for amplifying 99 bp target DNA fragments from $\lambda$-DNA template was pumped into the microchannels from a $50 \mu \mathrm{l}$ syringe by a syringe pump and collected from the outlet port into a $0.2 \mathrm{ml}$ tube. The amplicons were mixed with $1 \mathrm{X}$ Blue/Orange Dye and injected into an agarose gel for electrophoresis. The product was imaged using a Gel Logic 200 Imaging System (Kodak, New Haven, CT) with UV light. There was neither preheating of the DNA cocktail nor BSA coating for the microchannels. Flow velocities of $1 \mathrm{~mm} / \mathrm{s}, 2 \mathrm{~mm} / \mathrm{s}$, and 3 $\mathrm{mm} / \mathrm{s}$, corresponding to $0.048 \mu \mathrm{l} / \mathrm{min}, 0.096 \mu \mathrm{l} / \mathrm{min}$, and 0.144 $\mu \mathrm{l} / \mathrm{min}$, were used. Figure 7 shows the successful amplification results from the small footprint 20- and 25-turn CFPCR devices at different flow velocities. Total reaction times as fast as $5.1 \mathrm{~min}$ (15.3 s cycle $\left.^{-1}\right)$ were achieved for the 20-turn CFPCR device at a 


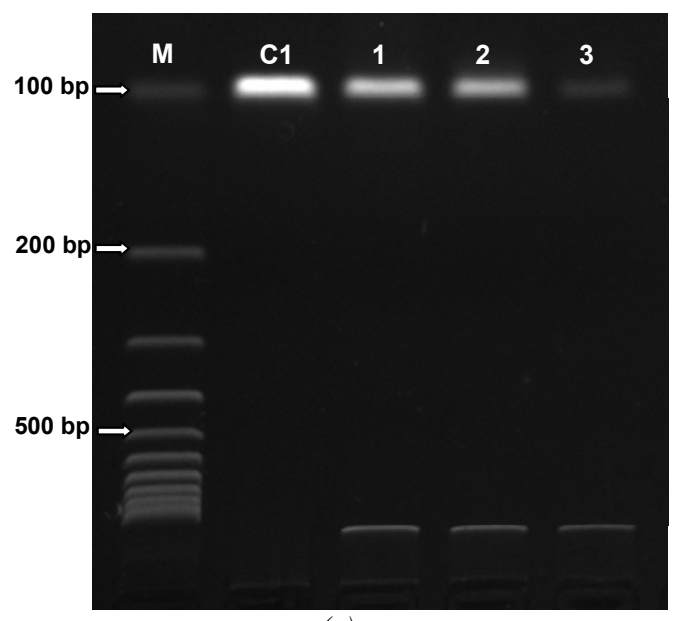

(a)

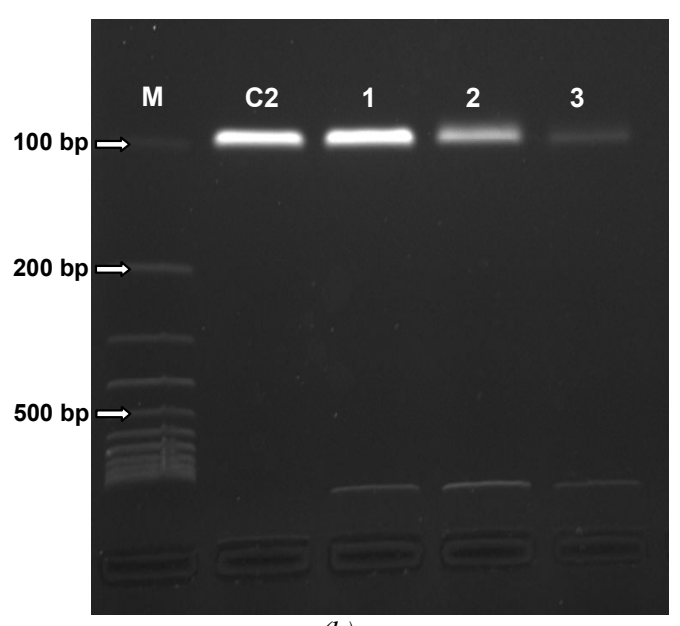

(b)

Figure 7: Gel electrophoresis images of the $99 \mathrm{bp}$ DNA fragments generated from (a) 20-turn and (b) 25-turn small footprint CFPCR devices. Lane $m$ represents DNA sizing markers (from 100 to $1000 \mathrm{bp}$ ); $\mathrm{Cl}$ : 20-turn control from a commercial PCR cycler; C2: 25-turn control from a commercial PCR cycler; 1: flow velocity of $1 \mathrm{~mm} / \mathrm{s}, 2$ : flow velocity of $2 \mathrm{~mm} / \mathrm{s}$, 3: flow velocity of $3 \mathrm{~mm} / \mathrm{s}$.

flow velocity of $3 \mathrm{~mm} / \mathrm{s}$.

\section{CONCLUSIONS}

Small footprint CFPCR devices, each device confined to a footprint of $8 \times 8 \mathrm{~mm}^{2}$, were designed and double-side hot embossed as part of a high throughput 96-well CFPCR multi-reactor platform. Acceptable replication fidelity over the entire surface area was obtained from double-sided micro molding of CFPCR PC chips. A custom-designed thermal bonding apparatus yielded proper sealing of double-side molded PC chips without leakage between the microchannels. Such small footprint, 20- and 25-turn CFPCR devices showed successful DNA amplification of 99-bp target DNA fragments from a $48 \mathrm{kbp} \lambda$-DNA template at different flow velocities.

Small footprint CFPCR devices demonstrated in this work will enable processing of multiple PCR samples in parallel with the development of a heater module and a fluidic control module in a titer plate-based CFPCR multi-reactor platform for fast PCR process optimization and high throughput PCR applications, and will also offer the capability of integration with other microfluidic analytical devices.

\section{ACKNOWLEDGEMENTS}

This work was supported by the National Science Foundation and the State of Louisiana Board of Regents Support Fund under grant number EPS-0346411, and the State of Louisiana Board of Regents Support Fund, Industrial Ties Program through grant number LEQSF(2005-08)-RD-B-04. The authors thank the Center for Advanced Microstructures and Devices (CAMD) at Louisiana State University for the microfabrication support.

\section{REFERENCES}

[1] T. K. Christopoulos, 1999, "Nucleic Acid Analysis", Anal. Chem., 71, pp. 425R-438R (1999).

[2] P. J. Obeid, T. K. Christopoulos, H. J. Crabtree, and C. J. Backhouse, "Microfabricated Device for DNA and RNA Amplification by Continuous-Flow Polymerase Chain Reaction and Reverse Transcription-Polymerase Chain Reaction with Cycle Number Selection”, Anal. Chem., 75, pp. 288-295 (2003).

[3] C. Zang and D. Xing, "Miniaturized PCR Chips for Nucleic Acid Amplification and Analysis: Latest Advances and Future Trends", Nucleic Acids Research, 35(13), pp. 4223-4237 (2007).

[4] M. A. Northrup, M. T. Chang, R. M. White, and R. T. Watson, "DNA Amplification in a Microfabricated Reaction Chamber", Proceedings of the 7th International Conference on Solid-State Sensors and Actuators (Transducers '93), Yokohama, Japan, 6/ 07-10/93, pp. 924-926.

[5] C. J. Easley, J. M. Karlinsey, and J. P. Landers, "On-Chip Pressure Injection for Integration of Infrared-Mediated DNA Amplification with Electrophoretic Separation", Lab Chip, 6, pp. 601-610 (2006).

[6] M. U. Kopp, A. J. deMello, and A. Manz, "Chemical Amplification: Continuous-Flow PCR on a Chip", Science, 280, pp. 1046-1048 (1998).

[7] M. Hashimoto, P.-C. Chen, M. W. Mitchell, D. E. Nikitopoulos, S. A. Soper, and M. C., Murphy, "Rapid PCR in a Continuous Flow Device", Lab Chip, 4, pp. 638-645 (2004).

[8] C. N. Liu, N. M. Toriello, and R. A. Mathies, "Multichannel PCR-CE Microdevice for Genetic Analysis", Anal. Chem., 78, pp. 5474-5479 (2006).

[9] Z.-Q. Zou, X. Chen, Q.-H. Jin, M.-S. Yang, and J.-L. Zhao, “A Novel Miniaturized PCR Multi-Reactor Array Fabricated Using Flip-Chip Bonding Techniques", J. Micromech. Microeng., 15, pp.1476-1481 (2005).

[10] Microplate Standards Development Committee (2004) For Microplates - Footprint Dimensions - ANSI/SBS 1-2004, eds. Secretariat Society for Biomolecular Screening. Danbury, CT.

[11] D. S. Park, P.-C. Chen, B. H. You, N. Kim, T. Park, P. Datta, Y. Desta, S. A. Soper, D. E. Nikitopoulos, and M. C. Murphy, "Optimization of Geometry for Continuous Flow PCR Devices in a Titer Plate-Based PCR Multi-Reactor Platform”, Proc. ASME IMECE 2007, IMECE2007-42135.

[12] P.-C. Chen, D. E. Nikitopoulos, S. A. Soper, and M. C. Murphy, "Temperature Distribution Effects on Micro-CFPCR Performance", Biomedical Microdevices, 10(2), pp. 141-152 (2008).

[13] D. S.-W. Park, M. L. Hupert, M. A. Witek, B. H. You, P. Datta, J. Guy, J.-B. Lee, S. A. Soper, D. E. Nikitopoulos, and M. C. Murphy, "A Titer Plate-Based Polymer Microfluidic Platform for High Throughput Nucleic Acid Purification", Biomedical Microdevices, 10(1), pp. 21-33 (2008). 